\title{
Gemtuzumab Ozogamicin
}

National Cancer Institute

\section{Source}

National Cancer Institute. Gemtuzumab Ozogamicin. NCI Thesaurus. Code C1806.

A recombinant, humanized anti-CD33 monoclonal antibody attached to the cytotoxic antitumor antibiotic calicheamicin. In this conjug ate, the antibody binds to and is internalized by tumor cells expressing CD33 antigen (a sialic acid-dependent glycoprotein commonly found on the surface of leukemic blasts), thereby delivering the attached calicheamicin to CD33-expressing tumor cells. Calicheamicin binds to the minor groove of DNA, causing double strand DNA breaks and resulting in inhibition of DNA synthesis.

( $\mathrm{NCl04)}$ 